\title{
Ambulatory Home Oxygen: What Is the Evidence for Benefit, and Who Does It Help?
}

\author{
Gerard J Criner MD
}

\author{
Introduction \\ The Effects of Ambulatory Home Oxygen Therapy on Survival \\ Severe Hypoxemia \\ Mild-Moderate Hypoxemia \\ Effect of Long-Term Oxygen on Physiological and Functional Outcomes \\ Pulmonary Hemodynamics \\ Hematocrit \\ Cognitive Impairment \\ Dyspnea \\ Quality of Life \\ FEV $_{1}$ \\ Exercise \\ Comorbidities \\ Long-Term Oxygen in Other Lung Diseases \\ Interstitial Lung Diseases \\ Congestive Heart Failure \\ Cancer \\ Unresolved Issues Regarding Long-Term Oxygen Therapy \\ Summary
}

The beneficial effects of ambulatory home oxygen have been demonstrated since the 1950s, when Cotes and Gibson gave oxygen to ambulatory COPD patients from small portable high pressures cylinders in the United Kingdom. Over the ensuing 7 decades, oxygen has been prescribed to millions of COPD patients in the home setting. Additionally, it is common clinical practice to prescribe supplemental oxygen when chronic hypoxemic respiratory failure not due to COPD (eg, interstitial lung disease, pulmonary hypertension, kyphoscoliosis, and cystic fibrosis) is present or in patients with hypoxemia at hospital discharge following flares of their underlying chronic respiratory disorder, without any substantial evidence. Despite the importance of long-term oxygen therapy in clinical home management, there are many gaps in our current knowledge regarding its mechanisms of action, indications for prescription, and its effects on important patient outcomes. Research conducted in the 1970s and 1980s still provides the basis for clinical decision making and insurance coverage policies regarding long-term oxygen administration. Remarkably, little current research is being conducted to extend our knowledge regarding the indications, mechanisms, and benefits of long-term oxygen therapy. This review will focus on our current knowledge of the end points for supplemental oxygen at home, such as mortality, effects on functional performance, sensation of dyspnea, cognitive function, and quality of life, and highlight areas where future research is needed. Key words: COPD; ambulatory oxygen; emphysema. [Respir Care 2013;58(1):4862. (C) 2013 Daedalus Enterprises] 


\section{AMBULATORY OXYGEN IN COPD}

\section{Introduction}

For the last 70 years, oxygen has been utilized as a therapeutic tool to attenuate the detrimental effects of hypoxemia and reverse the complications of hypoxemia in patients with advanced lung disease. It is estimated that over 800,000 patients annually receive long-term oxygen therapy in the United States, at an annual cost of approximately $\$ 2$ billion. ${ }^{1}$ Medicare charges for oxygen were $\$ 2.2$ billion in 2002 , with an annual inflation rate of 12 $13 \%$ per year. ${ }^{2}$ Ambulatory oxygen therapy has been provided at home for the purposes of reducing mortality, improving functional status, palliating the devastating consequences of dyspnea, and overall improving quality of life. ${ }^{3-6}$

Oxygen therapy in stable COPD has been utilized for the purposes of normalizing $\mathrm{P}_{\mathrm{aO}}$, reducing ventilatory drive during exercise, and reducing the sensation of dyspnea. The normalization of $\mathrm{P}_{\mathrm{aO}}$ has been the basis of trials with the goal of prolonging survival in patients with COPD and severe resting hypoxemia. If untreated, hypoxia can progress to tissue hypoxia, which has adverse effects on vital organ function. Hypoxemia can induce vasodilatation of the peripheral vascular beds, thereby causing an increase in heart rate and cardiac output and improved oxygen delivery. High levels of erythropoietin due to persistent hypoxemia induce secondary erythrocytosis in an attempt to increase oxygen capacity, which also can cause increased serum viscosity. All of these mechanisms may have detrimental long-term effects on cardiac and hematologic function and lead to pulmonary hypertension, right ventricular dysfunction, and severe secondary polycythemia, all of which can lead to increased mortality. Increasing $\mathrm{F}_{\mathrm{IO}_{2}}$ has been reported to reduce chemoreceptor input and minute ventilation, which may be beneficial in COPD patients by reducing lactate production in exercising muscles, improving oxygen delivery to metabolizing tissues, and overall decreasing the development of dynamic hyperinflation. Oxygen may also help to reduce the sensation of breathless-

Dr Criner is affiliated with the Division of Pulmonary and Critical Care Medicine, Department of Medicine, Temple University School of Medicine, Philadelphia, Pennsylvania.

Dr Criner presented a version of this paper at the 50th ResPiratory CARE Journal Conference, "Oxygen," held April 13-14, 2012, in San Francisco, California.

The author has disclosed no conflicts of interest.

Correspondence: Gerard J Criner MD, Division of Pulmonary and Critical Care Medicine, 845 Parkinson Pavilion, Temple University Hospital, 3401 N Broad Street, Philadelphia PA 19140. E-mail: Gerard.Criner@ tuhs.temple.edu.

DOI: $10.4187 /$ respcare.01918 ness by providing a relatively rapid reduction in ventilatory drive, which translates into an improvement in the sensation of dyspnea. ${ }^{1}$

Supplemental oxygen has not only been shown to affect the control of ventilation, but to regulate pulmonary blood flow and modulate gene expression and cellular activity and interaction throughout the body. ${ }^{7-9}$ These effects suggest that long-term oxygen benefits may exceed the metabolic effects of improved oxygen delivery and have an impact on enhancing remodeling or repair of the lung. Despite the above beneficial aspects of supplemental oxygen in the ambulatory patient, many of the above benefits are not demonstrated in all COPD patients, especially those with less severe levels of hypoxemia, and patient adherence to supplemental oxygen is variable and at times unpredictable. It is unclear whether the lack of oxygen utilization across all patient groups is related to barriers associated with the use of supplemental oxygen, as opposed to a lack of a broad benefit of supplemental oxygen use in the COPD patient population at large.

Additionally, it is a common clinical practice to prescribe supplemental oxygen without any substantial evidence when chronic hypoxemic respiratory failure not due to COPD (eg, interstitial lung disease, pulmonary hypertension, kyphoscoliosis, cystic fibrosis) mirrors the current criteria used in COPD patients. Additionally, many COPD patients and others, as described above, have oxygen therapy prescribed when they remain hypoxemic at discharge from the hospital following an exacerbation of their underlying chronic disease, despite a lack of data that support the short or long-term benefits of oxygen use in these patient groups.

In this paper we will review the benefits of ambulatory home oxygen on mortality, exercise performance, sensation of dyspnea, functional status, and quality of life.

\section{The Effects of Ambulatory Home Oxygen Therapy on Survival}

\section{Severe Hypoxemia}

Chronic hypoxemia that leads to development of cor pulmonale portends a poor prognosis with mortality, ranging from $30-100 \%$. Early, non-controlled studies reported a reduction in mortality in patients with COPD, severe hypoxemia, and cor pulmonale with the use of continuous oxygen therapy for periods ranging from 7 to 41 months. ${ }^{3,5}$ Two carefully conducted randomized controlled trials demonstrated the beneficial effects of long-term oxygen therapy on survival in patients with COPD and severe resting hypoxemia. These 2 landmarks studies were performed in the late 1970s: the Nocturnal Oxygen Therapy Trial (NOTT) and the British Medical Research Council (MRC) LongTerm Domiciliary Oxygen Therapy Trial examined the 
effects of long-term oxygen treatment on survival and physiologic function in patients with severe chronic bronchitis and emphysema.

The British MRC trial enrolled 87 patients, all younger than 70 years of age, for chronic bronchitis or emphysema and who had irreversible air-flow obstruction $\left(\mathrm{FEV}_{1}\right.$ range 0.5-0.75 L), severe hypoxemia $\left(\mathrm{P}_{\mathrm{aO}_{2}}\right.$ range 49.4$51.8 \mathrm{~mm} \mathrm{Hg})$, carbon dioxide retention $\left(\mathrm{P}_{\mathrm{aCO}_{2}}\right.$ $56-60 \mathrm{~mm} \mathrm{Hg}$ ), and a history of cor pulmonale (mean pulmonary artery pressure range $32.3-35.0 \mathrm{~mm} \mathrm{Hg}$ ). ${ }^{10}$ Those randomized to oxygen were given $2 \mathrm{~L} / \mathrm{min}$ of oxygen via nasal prongs for at least 15 hours daily. At 5 years of follow-up, 19 of 42 oxygen treated patients died, compared with 30 of 45 control patients who did not receive supplemental oxygen. Mortality was highest in the subgroup of patients that had the highest elevations in baseline $\mathrm{P}_{\mathrm{aCO}}$ and red cell mass. Although mortality was beneficially affected by long-term oxygen use, there were no statistically significant differences in the rate of decrease in $\mathrm{FEV}_{1}$ or $\mathrm{P}_{\mathrm{aO}_{2}}$ or increases in $\mathrm{P}_{\mathrm{aCO}}$, red cell mass, or pulmonary artery pressures. However, there was a trend that long-term oxygen therapy prevented a progressive decrease in $\mathrm{P}_{\mathrm{aO}_{2}}$ and the rate of increase in pulmonary vascular resistance without provoking further increases in $\mathrm{P}_{\mathrm{aCO}}$.

The NOTT evaluated 203 hypoxemic COPD patients who were randomized to receive either continuous oxygen therapy or 12 hours of nocturnal oxygen therapy. ${ }^{11}$ All subjects were followed for at least 12 months to determine the effects of oxygen on survival, pulmonary vascular pressures, quality of life, and neuropsychological function. Mortality in the 203 patients was followed for an average of 19.3 months. Twelve month mortality in the nocturnal oxygen group was $20.6 \%$, versus $11.9 \%$ in the continuous oxygen therapy group. In the nocturnal oxygen group, 24 month mortality was $40.8 \%$, versus $22.4 \%$ in the continuous oxygen treatment group. Hematocrit values were more reduced in patients on continuous oxygen therapy, versus those randomized to nocturnal treatment, as was pulmonary vascular resistance. However, no effect of continuous versus nocturnal oxygen therapy was found on other physiologic parameters, such as $\mathrm{FEV}_{1}$, mean pulmonary artery pressures, lung volumes, or arterial blood gases.

It should be noted, however, that, although both of the above studies showed improved survival, there were some important differences between the 2 studies. MRC patients tended to be more ill and had more evidence suggesting hypercapnia or cor pulmonale. A substantial number of subjects in the MRC study continued to smoke even after enrollment into the trial $27 \%$ in the control group and $44 \%$ in the placebo group). The MRC study found no effect of nocturnal oxygen therapy versus no oxygen therapy on physiological variables, while NOTT found greater decreases in hematocrit and pulmonary vascular resistance

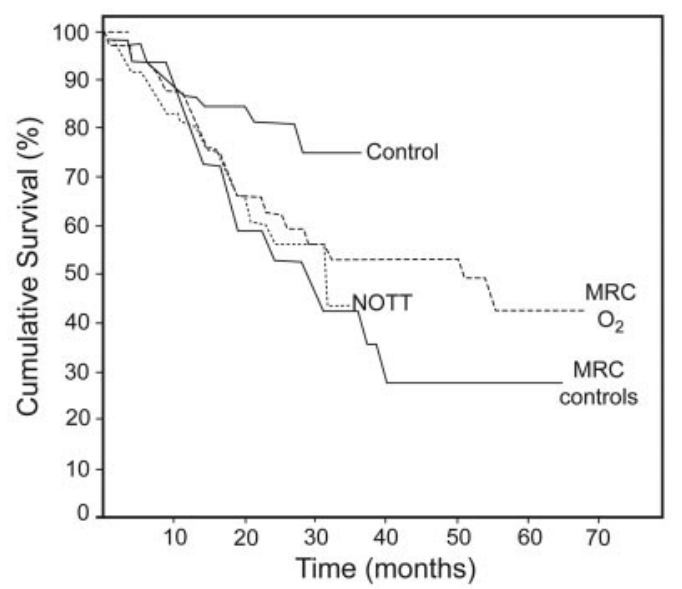

Fig. 1. Long-term oxygen therapy in males $<70$ years old, in the Medical Research Council (MRC) controlled trial and the National Institutes of Health Nocturnal Oxygen Therapy Trial (NOTT). (From Reference 6, with permission.)

in those who used continuous oxygen therapy versus nocturnal use only.

Despite these differences between the 2 trials, however, the results of these 2 trials indicate that the duration of use of supplemental oxygen is an important factor in improving survival in COPD patients with severe resting hypoxemia (Fig. 1). Median survival in those using oxygen 18 hours per day were approximately 2 -fold longer than in those receiving no oxygen therapy. Subsequent uncontrolled studies examining patient populations similar to the NOTT and MRC studies that were treated with oxygen have produced similar results.

\section{Mild-Moderate Hypoxemia}

In contrast to the NOTT and MRC studies, 2 studies have reported that supplemental oxygen use in COPD outpatients with mild to moderate resting hypoxemia has no effect on survival. ${ }^{12,13}$ Both of these studies did not use other indices of disease severity, and enrolled only 81 subjects who were followed for a maximum of 85 or 36 months. The average daily use of oxygen in the 2 studies was approximately 13.5 hours in those randomized to receive oxygen. This duration may be inadequate because COPD patients receiving long-term oxygen therapy have been reported to have an increase in pulmonary vascular resistance when oxygen was stopped for as little as 3 hours a day. ${ }^{14}$ Although neither of the studies was powered to examine the effect of oxygen in mild to moderate resting hypoxemia on survival, the similarities of outcomes between the treated and control groups suggest that patients with less severe COPD fail to derive any survival benefit from long-term oxygen therapy. ${ }^{12,13}$

Despite the above data, clinicians continue to prescribe oxygen therapy to patients with severe COPD, even when 


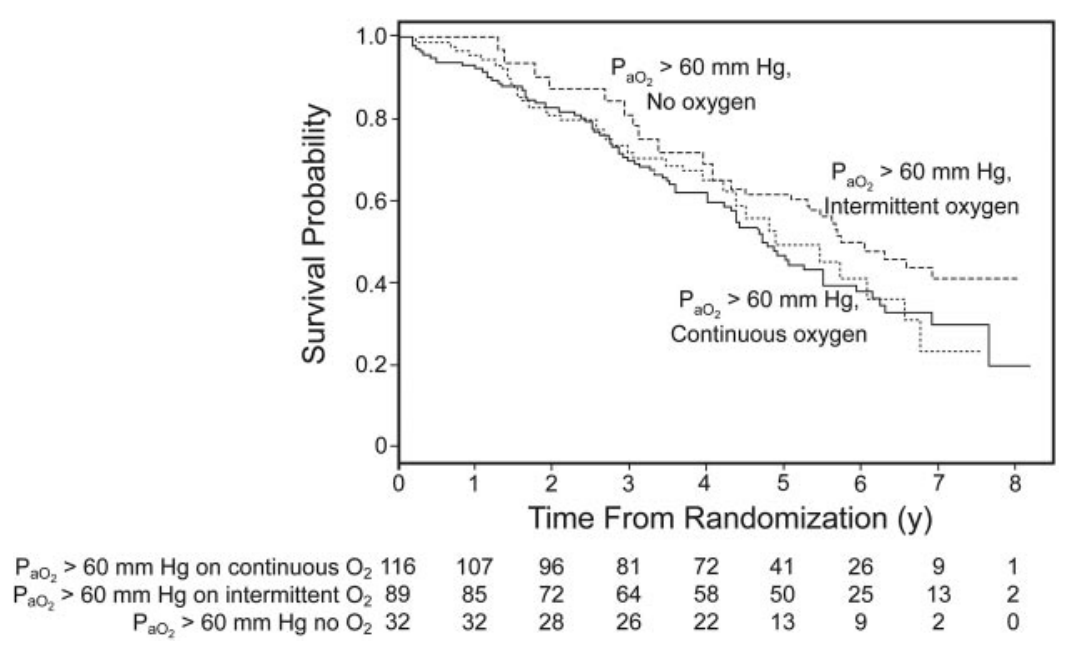

Fig. 2. Survival analysis of patients in the National Emphysema Treatment Trial. (From Reference 15, with permission.)

severe resting hypoxemia is absent. In an analysis of patients enrolled in the National Emphysema Treatment Trial, $33.8 \%$ of the patients with severe emphysema and FEV $<45 \%$ of predicted without severe resting hypoxemia received continuous oxygen therapy. ${ }^{15}$ The National Emphysema Treatment Trial patients receiving continuous oxygen had worse dyspnea and poorer quality of life and more frequent oxygen saturation with exercise, compared to a comparable National Emphysema Treatment Trial subgroup not receiving oxygen. In those patients who utilized oxygen therapy continuously, a higher mortality was observed, in contrast to a similar comparison group that did not use oxygen (Fig. 2). These data illustrate a divergence between evidence-based studies reporting those who are most likely to benefit from continuous oxygen, compared to the characteristics of patients who are prescribed oxygen in current clinical practice.

\section{Effect of Long-Term Oxygen on Physiological and Functional Outcomes}

\section{Pulmonary Hemodynamics}

Pulmonary hypertension is a common complication of severe COPD and chronic hypoxemia, and is associated with increased mortality, risk for hospitalization, and duration of hospitalization that is independent of the degree of air-flow obstruction. Although it has been suspected that the increased life expectancy with supplemental oxygen in COPD patients with severe hypoxemia is attributable to an improvement in pulmonary hemodynamics, data supporting that notion are weak and contradictory. The NOTT reported that oxygen therapy in hypoxemic COPD patients was associated with favorable but minimal improvements in the magnitude of pulmonary hypertension at rest and during exercise. ${ }^{16}$ Additionally, NOTT data suggested that improvements in pulmonary hemodynamics secondary to oxygen supplementation were enhanced in the group of patients who used oxygen continuously, compared to those who used it on an intermittent daily basis. ${ }^{16}$ However, improvements in survival in NOTT patients receiving continuous oxygen, compared to those who received only nocturnal oxygen, were not attributable to changes in pulmonary hemodynamics, and the acute response to oxygen administration on pulmonary hemodynamics did not predict the long-term effects of oxygen on survival.

Three subsequent studies have examined the effect of oxygen on the pulmonary circulation and have attempted to determine: whether the effect of long-term oxygen therapy and pulmonary hypertension is maintained longer than 6 months in COPD; whether the acute effects of oxygen administration on pulmonary artery pressures predicts survival in hypoxemic COPD patients treated with long-term oxygen; and the effect of acute withdrawal of supplemental oxygen on pulmonary artery pressures in COPD.

Weitzenblum et al studied 16 patients with severe COPD $\left(\mathrm{FEV}_{1} 0.89 \pm 0.28 \mathrm{~L}\right)$ who were hypoxemic at rest $\left(\mathrm{P}_{\mathrm{aO}_{2}} 50.2 \pm 6.6 \mathrm{~mm} \mathrm{Hg}\right)$ and moderately hypercapnic $\left(\mathrm{P}_{\mathrm{aCO}_{2}} 51 \pm 6.4 \mathrm{~mm} \mathrm{Hg}\right)$ by conducting 3 consecutive right heart catheterizations before and after oxygen therapy. ${ }^{17}$ Oxygen therapy was provided $15-18 \mathrm{~h} / \mathrm{d}$ and prescribed at flow rates based on usual criteria. After longterm oxygen administration was initiated, with subsequent follow-up at an average of 1/2-2 years, pulmonary artery mean pressure decreased from $28.0 \pm 7.4 \mathrm{~mm} \mathrm{Hg}$ to $23.9 \pm 6.6 \mathrm{~mm} \mathrm{Hg}(P<.005)$. Following the administration of supplemental oxygen, a yearly decrease in mean pulmonary artery pressure of $2.15 \pm 4.4 \mathrm{~mm} \mathrm{Hg}$ was observed. These data were interpreted as demonstrating that long-term oxygen therapy has a beneficial effect on reducing pulmonary artery pressures for a period greater than 6 months. 
Sliwinski and colleagues studied the acute effects of supplemental oxygen on pulmonary hemodynamics as a predictor of long-term outcome in 46 severe COPD patients who otherwise qualified for long-term oxygen administration. ${ }^{18}$ Thirty-nine of the subjects had a decrease in mean pulmonary artery pressure $\leq 5 \mathrm{~mm} \mathrm{Hg}$ in response to an acute administration of oxygen, and were called oxygen non-responders. In 7 patients, mean pulmonary artery pressure decreased $>5 \mathrm{~mm} \mathrm{Hg}$, and they were labeled oxygen responders. Patients were then prescribed long-term oxygen therapy by conventional criteria for 2 years or until death. Two-year survival rate was $69 \%$ in the non-responders and 50\% in the responders. From these data it appears that the long-term use of oxygen may significantly improve survival, despite the lack of an acute oxygen effect on reducing pulmonary artery pressures.

Selinger et al performed repeated right heart catheterizations in 20 stable hypoxemic COPD patients while receiving supplemental oxygen, and then after interrupting the use of oxygen to determine whether reductions in pulmonary artery pressures were related to the daily duration of oxygen use. ${ }^{14}$ When oxygen therapy was withdrawn, the mean $\mathrm{P}_{\mathrm{aO}_{2}}$ decreased from $74 \pm 4 \mathrm{~mm} \mathrm{Hg}$ to $55 \pm 2 \mathrm{~mm} \mathrm{Hg}$. Pulmonary artery pressures significantly increased at rest and nearly doubled with exercise. Discontinuation of oxygen reduced the stroke volume index and increased the pulmonary vascular index by approximately $30 \%$. These alterations occurred gradually and reached steady state levels 2-3 hours following oxygen discontinuation. These data suggest that an interruption in oxygen supplementation for several hours a day in chronically hypoxemic COPD patients can result in an elevation of pulmonary artery pressures at rest and during exertion.

A recent controlled trial has reported that a 3-month period of nitric oxide and oxygen inhalation leads to a sustained improvement in resting pulmonary hemodynamics in severe COPD patients with secondary pulmonary hypertension, compared to oxygen treatment alone. ${ }^{19}$ Whether a combination of nitric oxide and oxygen treatment leads to an improvement in survival in severe COPD patients with secondary pulmonary hypertension is unknown at present.

In summary, the above data show that inhalation of supplemental oxygen with hypoxemic COPD produces favorable but minimal changes in the magnitude of pulmonary hypertension at rest and during exercise. Furthermore, it also suggests that favorable changes in pulmonary hemodynamics secondary to oxygen supplementation are enhanced in patients that receive oxygen continuously, compared to those who receive it on an intermittent basis. Improvements in survival in COPD patients receiving continuous versus nocturnal oxygen therapy is difficult to attribute solely to changes in pulmonary hemodynamics, based on the available data, and the acute response to administration of oxygen on pulmonary hemodynamics does not appear to predict the long-term effects of oxygen on survival. Further studies are required to determine the causal relationship of oxygen supplementation and pulmonary hemodynamics on survival and which subgroup of patients with pulmonary hypertension and hypoxemia in COPD are most likely to benefit from long-term oxygen administration.

\section{Hematocrit}

Hematocrit values in COPD reflect the balance between chronic hypoxemia stimulating erythropoiesis, and comorbidities and chronic inflammation suppressing erythropoiesis. In NOTT, patients with a high pulmonary vascular resistance and hematocrit showed the highest mortality. ${ }^{11}$ After 6 months of supplemental oxygen, a significant reduction in pulmonary vascular resistance and hematocrit was observed, but the long-term effects of this response on mortality in NOTT were not demonstrated. A recent retrospective, observational study evaluated the prognostic value of hematocrit in 2,524 severe COPD patients who received long-term oxygen therapy. ${ }^{20}$ Lower hematocrit values at baseline before implementation of long-term oxygen therapy was associated with worse survival. Celli et al similarly reported that lower hematocrit values in COPD patients were associated with increased mortality. ${ }^{21}$ At present, the prognostic value of low hematocrit values in severe COPD and the effects of supplemental oxygen on affecting the hematocrit or erythropoietin production are unclear and require further study.

\section{Cognitive Impairment}

Several features of COPD may contribute to cognitive dysfunction, including hypoxemia, cerebrovascular and cardiovascular disease, and limited physical activity that leads to an increase in social isolation. In NOTT, patients who received 6 months of long-term oxygen therapy were found to have improved alertness, motor speed, and hand grip but not improved emotional status or quality of life. ${ }^{22}$ An additional study in COPD patients after 3 months of long-term oxygen therapy demonstrated a slight positive effect of oxygen use on cerebral blood flow, autonomic function, and neuropsychologic status. ${ }^{23} \mathrm{~A}$ recent study of cognitive function in 1,202 COPD patients examined potential risk factors for cognitive impairment in comparison to age-matched normal controls. ${ }^{24}$ COPD was associated with an increased risk of cognitive impairment (odds ratio 2.42, 95\% CI 1.043-6.64). In the COPD cohort, a low baseline oxygen saturation was related to an increased risk of cognitive impairment (odds ratio for oxygen saturation $\leq 88 \% 5.45,95 \%$ CI $1.014-29.2, P=.048$ ). Regular use 
of supplemental oxygen decreased the risk for cognitive impairment (odds ratio 0.14, 95\% CI 0.07-0.27, $P<.001$ ). Despite the important implications of cognitive dysfunction in COPD patients, the effects of supplemental oxygen on improving cognitive dysfunction is understudied at the present time and merits further investigation.

\section{Dyspnea}

Dyspnea is a common and distressing symptom found in patients with COPD, especially in the advanced stages of the disease. Studies that have examined the use of oxygen therapy for treating breathlessness in patients with COPD at rest are limited in number and include small numbers of patients, with contradictory outcomes. More studies are found examining the short-term use of supplemental oxygen to decrease the sensation of breathlessness during exercise, and most studies show a reduction in dyspnea and an improvement in exercise endurance with the use of supplemental oxygen. Trials of long-term oxygen that measure breathlessness are few in number and report contradictory effects of long-term supplemental oxygen on reducing breathlessness.

A recent report of an expert working group of the Association of Palliative Care provides the following summary of evidence on the use of oxygen on decreasing breathlessness in COPD patients ${ }^{25}$ :

- There is evidence for and against using oxygen to palliate breathlessness at rest.

- The majority of patients using enriched oxygen during exercise experienced less breathlessness at equivalent levels of exercise, when compared to just inspiring room air oxygen.

- There is no evidence that pre-oxygenation reduces breathlessness during exercise.

- There is recent evidence that using oxygen may speed recovery from breathlessness, when given before or after exercise.

- Recent data suggest that the effects of ambulatory oxygen on quality of life over a longer term cannot be predicted from the patient's baseline characteristics or their acute/short-term response to oxygen therapy. Even when patients experience an acute short-term favorable effect with the use of oxygen therapy, a substantial proportion do not continue to use ambulatory oxygen because of poor tolerability.

\section{Quality of Life}

Improving quality of life is an important clinical outcome for patients with severe COPD; whether long-term oxygen administration improves quality of life in hypoxemic COPD patients is unclear at present. Quality of life was not addressed in the MRC trial, whereas in the NOTT a generalized measure, the Sickness Impact Profile was measured and demonstrated similar outcomes after 6 months of continuous or nocturnal oxygen treatment. ${ }^{11}$ Only 2 longitudinal studies have reported the effects of long-term oxygen on quality of life, perhaps because of ethical reasons or the difficulty of incorporating a placebocontrolled arm into the study design. ${ }^{5}$ Furthermore, it has been reported that the potential restriction on mobility imposed by using the oxygen device may be an important factor that counterbalances any improvement by using supplemental oxygen on quality of life. 26,27 Quality of life has been reported not to improve when patients received oxygen therapy for 6 months while using an oxygen concentrator, whereas other investigators have shown improved quality of life in patients who received liquid oxygen treatment, versus those who received oxygen via concentrators or small oxygen portable cylinders. ${ }^{27}$ In contrast, however, in a 1-year, randomized crossover trial, 24 COPD patients randomized to home oxygen therapy with an oxygen concentrator only, home oxygen concentrator plus as needed ambulatory oxygen, and home oxygen concentrator plus ambulatory compressed air treatment regimens showed no effect of additional ambulatory oxygen on quality of life, 6-min walk tests performance, or the daily duration of exposure to oxygen therapy. ${ }^{28}$

An important question is whether improvement of quality of life relates to either the severity or chronicity of hypoxemia and the pattern of supplemental oxygen use in COPD patients. Eaton et al reported that short-term use of ambulatory oxygen produced significant improvements in quality of life in COPD patients who demonstrated substantial exertional desaturation. ${ }^{29}$ However, the correction of oxygen desaturation was not predictive of the acute or longer term improvement in quality of life. Additionally, the same authors found that long-term oxygen administration in severe COPD patients was found to produce improvements in quality of life that were sustained/or further improved at 6 months. ${ }^{30}$ However, Nonoyama and colleagues reported no effect of ambulatory oxygen on quality of life measured by the Chronic Respiratory Questionnaire or St George's Respiratory Questionnaire, compared to standard therapy. ${ }^{31}$

It is important to stress that in a disease like COPD, which has high morbidity and impaired quality of life, with very few viable limited therapeutic options, the exploration of any therapy that may palliate the disease, regardless of a mortality effect, is beneficial. The contradictory nature and sparseness of the above data illustrate the need for further research in this important area. 
FEV $_{1}$

There are no current data to support the notion that long-term oxygen therapy may attenuate the decline in $\mathrm{FEV}_{1}$ or that $\mathrm{FEV}_{1}$ may be an important selection criterion to characterize the most appropriate candidates for longterm oxygen therapy. This is not surprising, since many of the comorbidities associated with COPD, such as pulmonary hypertension and cor pulmonale, polycythemia, congestive heart failure (CHF), stroke, and cerebrovascular disease, may have their negative consequences reversed or attenuated by the use of supplemental oxygen. The likelihood that the severity of air-flow obstruction may independently predict differential response to long-term oxygen therapy does not appear to be a plausible hypothesis.

\section{Exercise}

Exercise-Induced Oxygen Desaturation. Another group of COPD patients who may benefit from ambulatory oxygen therapy are those who are normoxemic or only mildly hypoxemic at rest but exhibit oxygen desaturation during physical activity. This patient group undoubtedly highlights the most controversial application of chronic oxygen therapy in COPD. Continuous oxygen therapy in this patient population has been shown to improve outcomes related to exercise performance and endurance capacity, but has not been shown to improve survival. Exertional desaturation is fairly common in advanced COPD, and Medicare and other healthcare providers pay for oxygen use in patients who exhibit only exertional desaturation. ${ }^{32}$ In both normal individuals and patients with COPD, supplemental oxygen improves exercise performance. This improvement has been thought to result from increasing oxygen transport, enabling greater utilization of oxygen by exercising muscles, avoiding or delaying the onset of inspiratory muscle fatigue, an improvement in right ventricular function, or a decrease in ventilatory work load because of decreased airways resistance.

The prevalence of exertional desaturation in COPD is unclear and depends on the characteristics of the population studied as well as the exercise protocol used to elicit oxygen desaturation. Soguel Schenkel et al reported in a group of 30 moderate to severe COPD patients (meaning $\mathrm{FEV}_{1} 37 \%$ of predicted, resting $\mathrm{P}_{\mathrm{aO}} 88 \mathrm{~mm} \mathrm{Hg}$ ) a greater number of desaturations during walking (13.1 desaturations $/ \mathrm{h}$ ), washing ( 12.6 desaturations $/ \mathrm{h}$ ), and eating ( $9.2 \mathrm{de}-$ saturations/h) than at rest $(5.3$ desaturations $/ \mathrm{h}){ }^{33}$ More desaturations occurred during the day, compared to the night ( 8.6 vs 6.8 desaturations/h, respectively). Performance during a 6-min walk test may predict the presence of important desaturations while performing the activities of daily living. Garcia-Talavera et al showed that COPD patients with moderate hypoxemia at rest did not have important desaturations during daytime activities if they did not desaturate during the first 3.5 min of a 6 -min walk test. ${ }^{34}$

Predicting Which Patients May Have Exercise Desaturation. Patients with predominantly an emphysematous phenotype and a lower diffusion capacity are more likely to desaturate during exertion, compared to patients with a similar degree of air-flow obstruction but an airway predominant rather than emphysema predominant phenotype. In 48 patients with COPD and resting $\mathrm{P}_{\mathrm{aO}_{2}}>55 \mathrm{~mm} \mathrm{Hg}$ at rest, $40 \%$ desaturated doing incremental lower extremity cycle ergometry testing. $\mathrm{FEV}_{1}$ and diffusion capacity were lower in those who desaturated, compared with individuals who did not desaturate $(0.89 \mathrm{~L}$ and $7.1 \mathrm{~mL} / \mathrm{min} /$ $\mathrm{mm} \mathrm{Hg}$ vs $1.44 \mathrm{~L}$ and $15.3 \mathrm{~mL} / \mathrm{min} / \mathrm{mm} \mathrm{Hg}$, respectively). ${ }^{35}$ No patient with a diffusion capacity of $>55 \%$ of predicted exhibited desaturation. Approximately $75 \%$ of patients with a diffusion capacity or $\mathrm{FEV}_{1}<35 \%$ of predicted desaturated during lower extremity cycling.

Resting oxygen saturation appears to be a useful tool to predict which patients may desaturate during exertion. Knower et al demonstrated in 81 COPD patients that approximately $50 \%$ of patients with a resting arterial oxygen saturation $\left(\mathrm{S}_{\mathrm{aO}_{2}}\right) \leq 95 \%$ experience desaturation during the 6-min walk test, in contrast to only $16 \%$ with a resting $\mathrm{S}_{\mathrm{aO}_{2}}>95 \%$ who desaturate with exertion. ${ }^{36} \mathrm{In}$ a subgroup of 70 patients with diffusion capacity measurements, no patient with a diffusion capacity $>36 \%$ and resting $\mathrm{S}_{\mathrm{aO}_{2}}$ $>95 \%$ desaturated during exercise. Moreover, Hadeli et al found the sensitivity and specificity for predicting exercise-induced desaturation at approximately $75 \%$ when the threshold for diffusion capacity was kept at $59.7 \%$ of predicted. ${ }^{37}$ Patients who perform an incremental shuttle walk test are more likely to desaturate, in comparison to those performing a 6-min walk test. ${ }^{38}$ Lewko et al reported that the mean drop in oxygen saturation was $-4.6 \%$ in 50 stable COPD patients performing a shuttle walk test, compared to $-2.8 \%$ in the same individuals performing a 6-min walk test. ${ }^{38}$

Exercise Desaturation and Mortality. A limited number of studies, comprised of small patient numbers, suggest that transient exertional desaturation may be associated with increased mortality. ${ }^{39-42}$ This has some biologic plausibility, since exercise-induced desaturation has been previously shown to correlate with the severity of pulmonary vascular disease in patients with only mild-moderate resting hypoxemia. ${ }^{43}$ However, limited information exists as to whether supplemental oxygen alters the course of the disease or prolongs survival. Overall, resting oxygen levels appear to have greater predictive power than exerciseinduced desaturation in predicting the course of the disease or response to long-term oxygen therapy. 
Effects of Oxygen Therapy on Exercise Tolerance. The most troubling symptoms that afflict COPD patient are dyspnea and impaired exercise tolerance. Several studies have shown the beneficial effects of supplemental oxygen on improving exercise performance in those who are hypoxemic at rest. Cotes and Gibson were among the first to assess the effects of supplemental oxygen on improving exercise performance in COPD patients and chronic respiratory failure. ${ }^{44}$ They found that breathing $30 \%$ oxygen significantly increased the time that subjects could walk on a treadmill, compared with breathing room air. Several other investigators confirmed their findings that COPD patients who were hypoxemic at rest had significant improvement in exercise performance when provided supplemental oxygen. Davidson et al showed a dose-dependent effect of supplemental oxygen on improving exercise performance in 17 patients; supplemental oxygen at a flow of $2 \mathrm{~L} / \mathrm{min}$ increased constant lower extremity cycling work load duration by $51 \%$, compared with room air, and by $80 \%$ with $4 \mathrm{~L}$ of oxygen per minute, and by $80 \%$ with $6 \mathrm{~L}$ of oxygen per minute. ${ }^{45}$ Legget and Flenley found that patients suffering from resting hypoxemia could increase exercise tolerance assessed by distance walking $12 \mathrm{~min}$ while breathing oxygen, but that this improvement in exercise tolerance was negated when subjects were forced to carry their portable oxygen supply. ${ }^{46}$ The improvement in walking distance was restored when supplemental oxygen use during the 12 min walk test was provided by wheeling the oxygen source on a light-weight trolley.

Determining which patients suffering from COPD may show improved exercise with supplemental oxygen has been somewhat problematic. Cotes and Gibson suggested that patients who benefited the most from supplemental oxygen improving exercise capacity had the largest venous admixture at rest, the greatest decrease in $\mathrm{P}_{\mathrm{aO}_{2}}$ during exertion, and the greatest increase in $\mathrm{P}_{\mathrm{aCO}_{2}}$ during exercise. ${ }^{44}$ Bradley and colleagues studied 26 severe COPD patients exercising on a treadmill while breathing supplemental compressed room air or oxygen. ${ }^{47}$ Although they found that treadmill exercise endurance time was significantly increased while inspiring supplemental oxygen, no relationship was found between increased exercise endurance and the degree of hypoxia, hypercarbia, or acidosis during exercise, or the changes in these parameters while breathing enriched oxygen, compared to breathing air.

Several small studies have suggested that supplemental oxygen enhances exercise performance in patients who are normoxemic at rest but desaturate with exertion. Voduc et al compared the effects of supplemental oxygen on exercise capacity in 16 hypoxemic COPD patients before and after participation in a pulmonary rehabilitation program. ${ }^{48}$ Supplemental oxygen therapy improved exercise duration by 75 seconds before participation in the pulmonary rehabilitation program, and by 153 seconds following pulmo- nary rehabilitation. A double-blind randomized placebo controlled trial was conducted in 20 stable COPD patients to assess oxygen desaturation during activities and to assess the short-term effects of supplemental oxygen. ${ }^{49} \mathrm{~Pa}-$ tients underwent three 6-min walk tests in random sequence: a baseline 6-min walk, and 6-min walk tests while breathing compressed air or oxygen. In patients who exhibited oxygen desaturation, supplemental oxygen, compared to compressed air inhalation, resulted in a $22 \%$ increase in the distance walked and a $36 \%$ reduction in the magnitude of dyspnea. In patients who did not desaturate, oxygen administration reduced the magnitude of dyspnea by $40 \%$, but the distance walked remained unchanged. Emtner et al studied whether non-hypoxemic COPD patients undergoing exercise training while breathing supplemental oxygen could achieve higher intensity and therefore improved exercise capacity, compared to patients breathing just room air. ${ }^{50} \mathrm{In}$ a double-blind trial conducted in 29 non-hypoxemic COPD patients, the oxygen training group increased training work rate more rapidly than the air training group. The mean \pm SD work rate during the last week was $62 \pm 19 \mathrm{~W}$ in the oxygen training group vs $52 \pm 22 \mathrm{~W}$ in the air training group $(P<.01)$. After training, endurance and the constant work rate increased more in the oxygen training group $(14.5 \mathrm{~min})$ than the air training group $(10.5 \mathrm{~min}, P<.05)$. At exercise isotime, breathing rate decreased 4 breaths/min in the oxygen training group and 1 breath/min in the air training group $(P=.001)$.

Other investigators have found limited or no benefit on exercise performance while using supplemental oxygen in COPD patients who are non-hypoxemic at rest. Eaton et al conducted a 12 week double-blind randomized crossover trial in 50 severe COPD patients (mean $\mathrm{FEV}_{1} 25.9 \pm 8.0 \%$ of predicted, resting $\mathrm{P}_{\mathrm{aO}_{2}} 9.2 \pm 1.0 \mathrm{kPa}, \mathrm{S}_{\mathrm{aO}_{2}}$ after 6-min walk $82 \pm 5.4 \%$ ), and $68 \%$ of the patients increased their 6-min walk distance $\geq 54 \mathrm{~m}$ or had a decreased Borg dyspnea score of $\geq 1$ unit. ${ }^{29}$ All measures on the Chronic Respiratory Questionnaire and levels of anxiety and depression determined by the Hospital Anxiety Depression Scale and general health, physical, and emotional roles on the Short Form-36 improved with supplemental oxygen. However, the improvements in patient-reported quality of life outcomes did not correlate with oxygen's effects on the 6-min walk distance or the Borg dyspnea score. Despite measurable beneficial effects, nearly half of the responders chose not to use continuous supplemental oxygen on the long term.

In another crossover study in 36 COPD patients (FEV $10.9 \mathrm{~L}$, resting $\mathrm{P}_{\mathrm{aO}_{2}} 69 \mathrm{~mm} \mathrm{Hg}$ ) there was no beneficial effect of supplemental oxygen on health status, exercise tolerance, or dyspnea, when receiving either 6 weeks of portable oxygen or air. ${ }^{51}$ In an additional crossover randomized trial comparing portable oxygen versus air in 
Table 1. Mechanisms by Which Oxygen Therapy May Improve Exercise Tolerance

Reduction in minute ventilation while inspiring oxygen

Improvements to increased peripheral oxygen delivery

Improvement in pulmonary hemodynamics and right-ventricular function

Improvements in respiratory and non-respiratory skeletal muscle function

Reduction in dyspnea

(Data from Reference 32.)

9 patients with a resting $\mathrm{P}_{\mathrm{aO}_{2}}<60 \mathrm{~mm} \mathrm{Hg}$, no differences in 6-min walk distances were found. ${ }^{52}$ In a single blind trial in 20 patients, no significant differences in 6-min walk distance were found after 8 weeks of treadmill exercise training using either supplemental oxygen or compressed air. ${ }^{53}$ Rooyackers et al examined the effect of inhaled oxygen or air on exercise performance and quality of life during 10 weeks of in-patient pulmonary rehabilitation in 24 COPD patients with exertional desaturation to $<90 \% .^{54}$ They reported that oxygen had no effect on quality of life or exercise performance. In a prospective randomized placebo controlled trial of air versus cylinder oxygen provided at $6 \mathrm{~L} / \mathrm{min}$ intranasally over 12 weeks in 143 moderate to severe COPD patients, no significant differences in any outcome were found between the groups receiving air or oxygen therapy. ${ }^{55}$ Finally a meta-analysis of 3 small studies with the purpose to determine the effectiveness of adding oxygen for exercise training, in comparison to exercise training without oxygen supplementation, in COPD reported that patients may exercise longer and have less shortness of breath when using oxygen during an exercise training program; however, it was not possible to determine which individuals should use oxygen during exercise training because of the small number of subjects involved and the lack of characterization of those most likely to benefit. ${ }^{56}$ Additionally, it was impossible to tell whether oxygen inhalation had any significant effect on shortness of breath while subjects performed the activities of daily living.

Mechanisms by Which Oxygen Therapy May Improve Exercise Tolerance. Identifying the mechanisms responsible for producing the improvements in exercise endurance with inspired oxygen has also proven to be problematic (Table 1). Although several investigators have found that inspiring enriched oxygen during exercise reduces the perception of breathlessness, the mechanisms for this effect have remained a matter of debate. Some investigators have attributed the reduction in perceived breathlessness to the effect of cold gas stimulating the nasal mucosal receptors rather than to an improvement in oxygenation levels. Swinburn and co-workers demonstrated in 12 patients with severe COPD and resting hypoxemia that inspiration of $28 \%$ oxygen, in contrast to compressed air, was associated with a significant improvement in $\mathrm{S}_{\mathrm{aO}_{2}}$ $(85.1+2.3 \%$ vs $93.1 \pm 1.4 \%)$ and a reduction in breathlessness. ${ }^{57}$ Additionally, when the patients breathed oxygen, minute ventilation was significantly reduced, when compared to when they breathed air. These investigators interpreted their data as showing that the increase in arterial oxygen associated with breathing enriched oxygen resulted in a reduction in minute ventilation, primarily due to a reduction in tidal volume.

Besides a reduction in minute ventilation while inspiring oxygen, other investigators have attributed oxygenrelated exercise improvements to increased peripheral oxygen delivery, an improvement in pulmonary hemodynamics and right ventricular function, or to improvements in respiratory and non-respiratory skeletal muscle function. Morrison and Stovall found that hypoxemic COPD patients who had improved exercise capacity with supplemental oxygen had significant increases in oxygen delivery during exercise, which was associated with increases in both cardiac output and oxygen content, in contrast to those who had no improvement in exercise endurance. ${ }^{58}$ Similar data suggesting a beneficial effect of supplemental oxygen on improving exercise capacity due to an improvement in central pulmonary hemodynamics and right ventricular function were demonstrated in the NOTT. ${ }^{16}$ In the NOTT, breathing oxygen was associated with a reduction in cardiac index, right ventricular stroke work index, and mean pulmonary artery pressures at rest. During cycling exercise while breathing oxygen, in contrast to breathing room air, reductions in right atrial pressure, mean pulmonary artery wedge pressure, pulmonary vascular resistance, and stroke work index were also reported. Although the above studies demonstrate that oxygen may beneficially impact pulmonary hemodynamics both at rest and with exercise, the correlation of improvements in central pulmonary hemodynamics and cardiac performance with increased exercise endurance while breathing supplemental oxygen is unclear at the present time.

Improvements in ventilatory muscle function have also been proposed as an additional mechanism of improved exercise endurance while inspiring supplemental oxygen. Bye et al reported, in a group of severely obstructed patients, that supplemental oxygen increased exercise performance, which was accompanied by reduction in minute ventilation and breathing frequency, in contrast to breathing air. ${ }^{59}$ In some of these individuals there was a delay in the appearance of the electromyographic pattern of diaphragm fatigue. Criner and Celli reported, in a crossover prospective randomized trial, that inspiring supplemental oxygen during exercise altered ventilatory muscle recruit- 
ment. ${ }^{60}$ In 6 subjects with severe COPD and mild hypoxemia at rest (mean $\mathrm{P}_{\mathrm{aO}_{2}} 66 \pm 6.2 \mathrm{~mm} \mathrm{Hg}$ ), measurement of transdiaphragmatic pressures during exercise suggested a redistribution of ventilatory muscle recruitment that enabled more dynamic work to be done by diaphragm and less by the accessory respiratory and abdominal expiratory muscles while breathing enriched oxygen, compared to air. Subsequent work by others suggest that exercising with oxygen in COPD results in a reduction in minute ventilation and an increase in expiratory time that results in less dynamic hyperinflation and thereby a much more favorable environment that enhances diaphragm mechanical action and reduces accessory respiratory muscle work. ${ }^{1,61}$

Supplemental oxygen may also have important cellular effects on skeletal muscle performance. Acute correction of hypoxemia with supplemental oxygen in COPD patients has been reported to decrease the ratio of organic phosphate to phosphocreatine and increase the resynthesis rate of creatine phosphate. ${ }^{62}$ Additional investigators have shown that an improvement in skeletal muscle energy metabolism may occur during long-term oxygen treatment in patients with severe COPD and chronic hypoxemia. ${ }^{63}$

The inconsistent results reported by studies examining the effects of supplemental oxygen on exercise endurance can in large part be explained by limitations in quality of the research that has examined this problem to date. A recent systematic review of randomized controlled trials that examined the short-term benefits of ambulatory oxygen in COPD suggests that ambulatory oxygen improves exercise performance in COPD; however, the clinical importance of the magnitude of the treatment effect is unclear at the present time. ${ }^{64}$ Most of the reported data come from studies that have small patient numbers and are conducted in variable COPD patient populations with a variety of different exercise outcomes being used to assess the effects of supplemental oxygen that is provided at different doses and for variable durations. Future quality research that takes these design issues into consideration are needed to determine the place of supplemental oxygen in determining the efficacy and mechanisms of this potentially important therapy.

Short Burst Oxygen Therapy. Short burst oxygen therapy describes brief intermittent uses of oxygen before or after exertion. ${ }^{65}$ It has been used in several ways, such as pre-oxygenation before exercise, for the treatment of breathlessness during recovery from exercise, or for the control of breathlessness at rest. Short burst oxygen therapy is predominantly utilized by COPD patients who are not hypoxemic at rest or with exercise, and is usually provided by oxygen cylinders rather than oxygen concentrators. Although early studies suggested that short burst oxygen reduced dyspnea and increased 6-min walk distance, sub- sequent studies have not demonstrated a reduction in breathlessness or improved walk test performance. ${ }^{61,66-71} \mathrm{~A}$ randomized single-blind crossover study showed that breathing oxygen at $40 \%$ concentration, but not air, for 15 min after exercise in 18 moderately severe COPD patients decreased the time for recovery of dynamic hyperinflation by an average of $6.61 \mathrm{~min} .{ }^{61}$ Neither the maximal level of dyspnea nor duration of breathlessness was improved by short burst oxygen therapy. In a recent prospective randomized trial, 30 moderate to severe COPD patients with $\mathrm{FEV}_{1}$ $<40 \%$ of predicted and resting oxygen saturation $\geq 93 \%$ were given $4 \mathrm{~L}$ of oxygen via a simple face mask, $4 \mathrm{~L}$ of air from a simple face mask, air from a fan, or no intervention. ${ }^{72}$ Oxygen therapy had no discernible effect on Borg dyspnea scores during recovery from exercise or shortening the recovery period of dyspnea. The benefits of short burst oxygen therapy remain to be determined.

\section{Comorbidities}

The comorbidities associated with COPD are being increasingly recognized as important contributors to the morbidity and mortality of the disease. Clinical practice guidelines do not provide any guidance regarding the use of long-term oxygen therapy in patients with COPD and important comorbidities. In fact, the body of research to date has extensively excluded patients with important comorbidities from participating in studies that have examined the use of long-term oxygen therapy in COPD. A recent retrospective study demonstrated that body mass index $<25 \mathrm{~kg} / \mathrm{m}^{2}$ and the presence of comorbidities are predictors of all-cause respiratory mortality in COPD patients treated with long-term oxygen therapy. ${ }^{73}$ It will be important in the future to study the true impact of long-term oxygen therapy on all-cause mortality in complex COPD patients. Although it is well known that cardiovascular and cerebrovascular comorbidities increase mortality risk in COPD, these comorbidities were never taken into account when examining the outcome of long-term oxygen therapy in prior studies of COPD patients. At the current time there are insufficient data to determine whether long-term oxygen therapy reduces cardiovascular/cerebrovascular and/or metabolic morbidity and mortality in hypoxemic COPD patients.

\section{Long-Term Oxygen in Other Lung Diseases}

\section{Interstitial Lung Diseases}

Hypoxemia is common in patients with interstitial lung diseases, especially those with idiopathic pulmonary fibrosis. Oxygen therapy may have the potential to either prolong or shorten survival in patients who suffer from idio- 
pathic pulmonary fibrosis or usual interstitial pneumonitis. Hypoxemia at rest and desaturation with exertion in patients with idiopathic pulmonary fibrosis have been reported to be variables that predict worsened prognosis. ${ }^{74,75}$ With progression of the disease, hypoxemia may contribute to the development or worsening of pulmonary hypertension, which can lead to right heart dysfunction or cor pulmonale. Oxygen therapy may reverse the component of pulmonary hypertension that is mediated by the presence of hypoxemia and may help to improve exercise performance and quality of life. Most of the data used to justify long-term oxygen therapy to improve survival in diffuse interstitial lung disease have been extrapolated from results obtained from long-term oxygen use in patients with emphysema and may not be relevant to patients with interstitial pulmonary fibrosis or usual interstitial pneumonia. Two studies, however, have assessed the acute effects of oxygen therapy in patients with a variety of interstitial lung diseases with moderate severity. ${ }^{76,77}$ The patients in these 2 studies all desaturated on exercise, and it is likely that oxygen therapy probably has a more significant effect in these individuals.

On the other hand, oxygen therapy may have little benefit or be harmful in patients who have idiopathic pulmonary fibrosis. Idiopathic pulmonary fibrosis in part may be due to oxygen mediated injury and oxygen therapy may increase tissue concentrations of toxic oxygen radicals. In a retrospective study of 487 Idiopathic pulmonary fibrosis patients, conducted by Douglas and colleagues, univariate analysis showed that oxygen use significantly shortened survival. ${ }^{78}$ However, when multivariate analysis was performed that was adjusted for age, sex, and disease severity, oxygen therapy was not found to be independently associated with a shortened survival. Their conclusion was that oxygen therapy was a marker of disease severity rather than being a toxic therapy that led to a shortened survival.

At present there are no prospective, randomized, and controlled trials that have examined the effect of short or long-term oxygen therapy on functional outcomes and survival in patients with idiopathic pulmonary fibrosis. However, it has been reported that oxygen therapy in this patient group is likely to improve other symptoms and overall quality of life, and has been used during rehabilitative exercise training to increase endurance. ${ }^{79,80}$ Currently oxygen therapy is considered to be a critical component of the management of idiopathic pulmonary fibrosis patients, but future data examining its use are required.

\section{Congestive Heart Failure}

CHF is the fastest growing cardiovascular disorder in the United States. It is estimated that CHF afflicts about 10 per 1,000 people who are $\geq 65$ years of age. Six million people in the United States suffer from heart failure, and approximately 670,000 new cases are diagnosed annually. ${ }^{81}$ CHF is the most common cause for hospitalization in the elderly, and in the Medicare patient population heart failure is the most common reason for hospital admission and readmission within 30 days of hospital discharge. Medicare currently supports the use of long-term oxygen therapy and hypoxia-related conditions that may be expected to improve with oxygen therapy such as CHF or pulmonary hypertension. However, data from large randomized controlled trials that demonstrate the benefits of long-term oxygen therapy on acute or long-term outcome such as functional status or survival are also lacking in patients with CHF.

There is more robust data regarding the effects of oxygen therapy on sleep-disordered breathing that accompanies CHF. Cheyne-Stokes respiration is an abnormal respiratory pattern that is associated with $\mathrm{CHF}$, and the crescendo-decrescendo alteration in tidal volume associated with periods of apnea or hypoxemia are thought to be compensatory mechanisms for fluctuating changes in the partial pressures of oxygen and carbon dioxide that result from reduced cardiac output in patients with advanced CHF. Hypoxemia clearly plays a central role in the initiation of Cheyne-Stokes respiration, and oxygen therapy may have a beneficial impact on decreasing its presence. In a randomized controlled study, Sasayama showed that nocturnal oxygen therapy in stable CHF patients with Cheyne-Stokes respiration and nocturnal hypoxemia may improve sleep disorder breathing, left ventricular function, and quality of life. Nocturnal oxygen therapy in CHF patients diagnosed with central sleep-disordered breathing and hypoxemia has also been shown to improve the apneahypoxemia index. ${ }^{82}$ Similar results have been reported in stable CHF patients with evidence of periodic breathing and hypoxemia that showed that nocturnal oxygen therapy improved periodic breathing and clinically important oxygen desaturation. ${ }^{83} \mathrm{Krachman}$ and colleagues, in a prospective randomized controlled trial, compared nocturnal oxygen therapy with CPAP in patients with CHF and Cheyne-Stokes respiration, and concluded that nocturnal oxygen therapy and CPAP were equally effective in decreasing the apnea-hypopnea index in CHF patients with Cheyne-Stokes respiration. ${ }^{84}$

An increase in exercise tolerance and decrease in dyspnea have been noted when some patients with heart failure breathe enriched oxygen. ${ }^{85,86}$ However, these studies involved small number of subjects and had substantial variation in the methods used to perform exercise and the levels of oxygenation utilized, and most patients did not have hypoxemia at rest or during exercise without supplemental oxygen. Future investigation is required to determine the efficacy of oxygen therapy in patients with CHF. 
Table 2. Summary of the Availability of Coverage for Long-Term Home Oxygen Treatment Under Medicare

\begin{tabular}{|c|c|c|c|c|}
\hline \multicolumn{2}{|c|}{ Measurement } & \multicolumn{3}{|c|}{ Condition for Testing* } \\
\hline $\begin{array}{l}\text { Arterial } \mathrm{O}_{2} \\
(\mathrm{~mm} \mathrm{Hg})\end{array}$ & $\begin{array}{c}\mathrm{O}_{2} \text { Saturation } \\
(\%)\end{array}$ & At Rest & During Exercise & During Sleep \\
\hline$<55$ & $<88$ & Available & Available $\dagger$ & Available \\
\hline $56-59$ & 89 & \multicolumn{3}{|l|}{$\begin{array}{l}\text { Available for dependent edema, pulmonary } \\
\text { hyper-tension, or hematocrit }>56\end{array}$} \\
\hline$\geq 60$ & $\geq 90$ & \multicolumn{3}{|c|}{ Coverage available only by special approval } \\
\hline Devices covered & & Stationary \pm ambulatory & Ambulatory \pm stationary & Stationary only \\
\hline \multicolumn{5}{|c|}{$\begin{array}{l}\text { * While breathing room air in a chronic stable state or no earlier than } 2 \text { days prior to hospital discharge. } \\
\dagger \text { Requires demonstration that supplemental } \mathrm{O}_{2} \text { improves the exercise-associated hypoxemia. } \\
\ddagger \text { Also available for subjects who show a greater than normal fall in arterial } \mathrm{O}_{2}(>10 \mathrm{~mm} \mathrm{Hg}) \text { or arterial } \mathrm{O}_{2} \text { saturation }(>5 \%) \text { during sleep with associated symptoms or signs reasonably } \\
\text { attributable to hypoxemia. } \\
\text { (Data from References 32, with permission.) }\end{array}$} \\
\hline
\end{tabular}

\section{Cancer}

Shortness of breath is common in patients with advanced cancer and may affect $50-70 \%$ of patients. Oxygen therapy to relieve breathlessness toward the end of life in patients with advanced malignancy is supported by consensus guidelines, and it is a common clinical practice. ${ }^{25}$ In a recent survey of over 600 palliative care specialist and pulmonary physicians, approximately 50\% reported that palliative oxygen therapy is beneficial, and $65 \%$ reported that the most common reason for prescribing oxygen therapy was refractory dyspnea. ${ }^{87}$ Despite this clinical practice, however, data demonstrating that supplemental oxygen is effective in palliating dyspnea in patients with advanced malignancy are lacking. In a recent meta-analysis of 134 patients from 3 studies, oxygen therapy failed to improve dyspnea in mildly or non-hypoxemic cancer patients. ${ }^{88}$ Similarly, in a recent prospective randomized controlled trial of nasal air versus nasal oxygen in patients with life-threatening disease who were receiving palliative care for dyspnea (malignancy comprised about $15 \%$ of the population), nasal oxygen provided no benefit, compared to compressed air. ${ }^{25,89}$

At the present time it appears that oxygen therapy benefits patients with advanced malignancy who demonstrate hypoxemia at rest or with exertion or who exhibit a reduction in breathlessness in response to oxygen therapy. Future data are needed to better characterize the patient population with advanced cancer that may benefit from oxygen therapy.

\section{Unresolved Issues Regarding Long-Term Oxygen Therapy}

Despite its clinical use for over 40 years, many questions remain regarding the efficacy and appropriate indications for the use of long-term oxygen therapy in patients
Table 3. Controversies Regarding Long-Term Oxygen Therapy in COPD

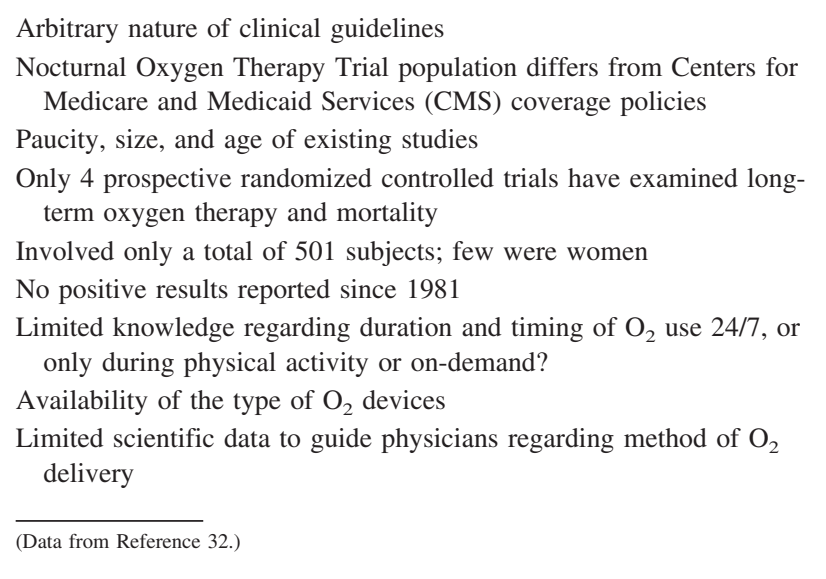

with advanced COPD, as well as in other diseases. Table 2 shows that Medicare approval for long-term oxygen therapy is based partially on expert opinion as well as evidence from positive randomized controlled trials. ${ }^{32,90} \mathrm{~A}$ recent National Heart, Lung, and Blood Institute workshop on long-term oxygen therapy in COPD highlighted the arbitrary nature of current clinical guidelines for oxygen use, the limited size and age of existing studies, limited knowledge regarding the duration and timing of oxygen use, and limitations in our knowledge regarding the optimal types of oxygen delivery devices (Table 3 ). ${ }^{32}$ Moreover, it is common knowledge that COPD patients frequently do not use their portable oxygen systems as prescribed by their physicians. In a recent report by Arnold et al, patients stated that they rarely received instructions from their physicians on how to use supplemental oxygen, they were unclear of the benefits of using oxygen, they were afraid that their oxygen device would run out of oxygen while using it, that the devices they were given for ambulatory oxygen were too heavy for them, and that the 


\section{AMBULATORY OXYGEN IN COPD}

lack of a support person while using oxygen was an important obstacle to why they failed to use ambulatory oxygen therapy. ${ }^{91}$ Casaburi and colleagues further demonstrated that patients use their oxygen devices less than prescribed, even when provided with lightweight ambulatory portable units. ${ }^{92}$

In an attempt to determine whether supplemental oxygen is beneficial in patients with mild to moderate hypoxemia at rest or normoxic individuals at rest with mild to moderate exertional desaturation, the National Heart, Lung, and Blood Institute and Centers for Medicare and Medicaid Services have jointly enacted the Long-Term Oxygen Treatment Trial (LOTT) ${ }^{93}$ LOTT seeks to determine if supplemental oxygen increases the time to a composite outcome of all-cause mortality or all-cause hospitalization in COPD patients with mild to moderate degrees of resting hypoxemia $\left(\mathrm{S}_{\mathrm{pO}_{2}} 89-93 \%\right)$ or resting $\mathrm{S}_{\mathrm{pO}_{2}}>93 \%$ and moderate oxygen desaturation during exertion). Primary outcomes of LOTT include death or hospitalization, and secondary outcomes include time to death, time to hospitalization, and both disease specific and general effects of changes in quality of life. The goal is to recruit 737 eligible patients who will be followed for at least a year; over 500 patients have been recruited by this date. Hopefully, LOTT will provide answers regarding the efficacy of longterm oxygen therapy in patients with moderate resting hypoxemia, the efficacy of long-term oxygen therapy in those normoxic at rest but who desaturate during activity, the optimal methods for enhancing adherence to long-term oxygen therapy, and the optimal timing and dosing of oxygen supplementation.

\section{Summary}

Long-term oxygen therapy is an important disease-modifying treatment that provides significant improvements in physiologic and functional outcomes as well as survival in patients with advanced COPD who have severe hypoxemia at rest. Future investigation is needed to determine the effects of supplemental oxygen in patients with less severe forms of the disease, who have mild to moderate hypoxemia at rest or with exertion, as well as in other lung diseases that are characterized by hypoxemia to determine the efficacy of long-term oxygen therapy on survival and/or functional outcomes.

\section{REFERENCES}

1. O'Donnell DE, D'Arsigny C, Webb KA. Effects of hyperoxia on ventilatory limitation during exercise in advanced chronic obstructive pulmonary disease. Am J Respir Crit Care Med 2001;163(4): 892-898.

2. Department of Health and Human Services Office of Inspector General. Medicare and FEHB payment rates for home oxygen equip- ment. Washington, DC: US Government Printing Office; 2005. Inspector General Publication Number OEI-09-03-00160.

3. Kim V, Benditt JO, Wise RA, Sharafkhaneh A. Oxygen therapy in chronic obstructive pulmonary disease. Proc Am Thorac Soc 2008; 5(4):513-518.

4. Stoller JK, Panos RJ, Krachman S, Doherty DE, Make B, Long-term Oxygen Treatment Trial Research Group. Oxygen therapy for patients with COPD: current evidence and the long-term oxygen treatment trial. Chest 2010;138(1):179-187.

5. Corrado A, Renda T, Bertini S. Long-term oxygen therapy in COPD: evidences and open questions of current indications. Monaldi Arch Chest Dis 2010;73(1):34-43.

6. Make B, Krachman S, Panos RJ, Doherty DE, Stoller JK. Oxygen therapy in advanced COPD: in whom does it work? Semin Respir Crit Care Med 2010;31(3):334-342.

7. Mitchell GS, Baker TL, Nanda SA, Fuller DD, Zabka AG, Hodgeman BA, et al. Invited review: intermittent hypoxia and respiratory plasticity. J Appl Physiol 2001;90(6):2466-2475.

8. Raj U, Shimoda L. Oxygen-dependent signaling in pulmonary vascular smooth muscle. Am J Physiol Lung Cell Mol Physiol 2002; 283(4):L671-L677.

9. Semenza GL. Regulation of metabolism by hypoxia-inducible factor 1. Cold Spring Harb Symp Quant Biol 2011;76:347-353.

10. Medical Research Council Working Party. Long-term domiciliary oxygen therapy in chronic hypoxic cor pulmonale complicating chronic bronchitis and emphysema. Lancet 1981;1(8222):681-686.

11. Nocturnal Oxygen Therapy Trial Group. Continuous or nocturnal oxygen therapy in hypoxemic chronic obstructive lung disease: a clinical trial. Ann Intern Med 1980;93(3):391-398.

12. Chaouat A, Weitzenblum E, Kessler R, Charpentier C, Enrhart M, Schott $\mathrm{R}$, et al. A randomized trial of nocturnal oxygen therapy in chronic obstructive pulmonary disease patients. Eur Respir J 1999; 14(5):1002-1008.

13. Górecka D, Gorzelak K, Sliwiński P, Tobiasz M, Zieliński J. Effect of long-term oxygen therapy on survival in patients with chronic obstructive pulmonary disease with moderate hypoxaemia. Thorax 1997;52(8):674-679.

14. Selinger SR, Kennedy TP, Buescher P, Terry P, Parham W, Gofreed $\mathrm{D}$, et al. Effects of removing oxygen from patients with chronic obstructive pulmonary disease. Am Rev Respir Dis 1987;136(1):8591.

15. Drummond MB, Blackford AL, Benditt JO, Make BJ, Sciurba FC, McCormack MC, et al. Continuous oxygen use in nonhypoxemic emphysema patients identifies a high-risk subset of patients: retrospective analysis of the National Emphysema Treatment Trial. Chest 2008;134(3):497-506.

16. Timms RM, Khaja FU, Williams GW. Hemodynamic response to oxygen therapy in chronic obstructive pulmonary disease. Ann Intern Med 1985;102(1):29-36.

17. Weitzenblum E, Sautegeau A, Ehrhart M, Mammosser M, Pelletier A. Long-term oxygen therapy can reverse the progression of pulmonary hypertension in patients with chronic obstructive pulmonary disease. Am Rev Respir Dis 1985;131(4):493-498.

18. Sliwinski P, Hawrylkiewicz I, Gorecka D, Zielinski J. Acute effect of oxygen on pulmonary arterial pressure does not predict survival on long-term oxygen therapy in patients with chronic obstructive pulmonary disease. Am Rev Respir Dis 1992;146(3):665-669.

19. Vonbank K, Ziesche R, Higenbottam TW, Stiebellehner L, Petkov $\mathrm{V}$, Schenk P, et al. Controlled prospective randomised trial on the effects on pulmonary haemodynamics of the ambulatory long term use of nitric oxide and oxygen in patients with severe COPD. Thorax 2003;58(4):289-293.

20. Chambellan A, Chailleux E, Similowski T, ANTADIR Observatory Group. Prognostic value of the hematocrit in patients with severe 


\section{AMBULATORY OXYGEN IN COPD}

COPD receiving long-term oxygen therapy. Chest 2005;128(3):12011208.

21. Celli BR, Cote CG, Marin JM, Casanova C, Montes de Oca M, Mendez RA, et al. The body-mass index, airflow obstruction, dyspnea, and exercise capacity index in chronic obstructive pulmonary disease. N Engl J Med 2004;350(10):1005-1012.

22. Heaton RK, Grant I, McSweeny AJ, Adams KM, Petty TL. Psychologic effects of continuous and nocturnal oxygen therapy in hypoxemic chronic obstructive pulmonary disease. Arch Intern Med 1983; 143(10):1941-1947.

23. Hjalmarsen A, Waterloo K, Dahl A, Jorde R, Viitanen M. Effect of long-term oxygen therapy on cognitive and neurological dysfunction in chronic obstructive pulmonary disease. Eur Neurol 1999;42(1): 27-35.

24. Thakur N, Blanc PD, Julian LJ, Yelin EH, Katz PP, Sidney S, et al. COPD and cognitive impairment: the role of hypoxemia and oxygen therapy. Int J Chron Obstruct Pulmon Dis 2010;5:263-269.

25. Booth S, Wade R, Johnson M, Kite S, Swannick M, Anderson H, et al. The use of oxygen in the palliation of breathlessness. A report of the expert working group of the Scientific Committee of the Association of Palliative Medicine. Respir Med 2004;98(1):66-77.

26. Andersson A, Strom K, Brodin H, Alton M, Boman G, Jakobsson P, et al. Domiciliary liquid oxygen versus concentrator treatment in chronic hypoxaemia: a cost-utility analysis. Eur Respir J 1998;12(6): 1284-1289.

27. Okubadejo AA, Jones PW, Wedzicha JA. Quality of life in patients with chronic obstructive pulmonary disease and severe hypoxaemia. Thorax 1996;51(1):44-47.

28. Lacasse Y, Lecours R, Pelletier C, Begin R, Maltais F. Randomised trial of ambulatory oxygen in oxygen-dependent COPD. Eur Respir J 2005;25(6):1032-1038.

29. Eaton T, Garrett JE, Young P, Fergusson W, Kolbe J, Rudkin S, et al. Ambulatory oxygen improves quality of life of COPD patients: a randomised controlled study. Eur Respir J 2002;20(2):306-312.

30. Eaton T, Lewis C, Young P, Kennedy Y, Garrett JE, Kolbe J. Longterm oxygen therapy improves health-related quality of life. Respir Med 2004;98(4):285-293.

31. Nonoyama ML, Brooks D, Guyatt GH, Goldstein RS. Effect of oxygen on health quality of life in patients with chronic obstructive pulmonary disease with transient exertional hypoxemia. Am J Respir Crit Care Med 2007;176(4):343-349.

32. Croxton TL, Bailey WC. Long-term oxygen treatment in chronic obstructive pulmonary disease: recommendations for future research: an NHLBI workshop report. Am J Respir Crit Care Med 2006; 174(4):373-378

33. Soguel Schenkel N, Burdet L, de Muralt B, Fitting JW. Oxygen saturation during daily activities in chronic obstructive pulmonary disease. Eur Respir J 1996;9(12):2584-2589.

34. Garcia-Talavera I, Garcia CH, Macario CC, de Torres JP, Celli BR, Aguirre-Jaime A. Time to desaturation in the 6-min walking distance test predicts 24-hour oximetry in COPD patients with a $\mathrm{P}_{\mathrm{O}_{2}}$ between 60 and 70mmHg. Respir Med 2008;102(7):1026-1032.

35. Owens GR, Rogers RM, Pennock BE, Levin D. The diffusing capacity as a predictor of arterial oxygen desaturation during exercise in patients with chronic obstructive pulmonary disease. N Engl J Med 1984;310(19):1218-1221.

36. Knower MT, Dunagan DP, Adair NE, Chin R,Jr. Baseline oxygen saturation predicts exercise desaturation below prescription threshold in patients with chronic obstructive pulmonary disease. Arch Intern Med 2001;161(5):732-736.

37. Hadeli KO, Siegel EM, Sherrill DL, Beck KC, Enright PL. Predictors of oxygen desaturation during submaximal exercise in 8,000 patients. Chest 2001;120(1):88-92.
38. Lewko A, Marshall J, Garrod R. Ambulatory oxygen therpay assessment: a comparative study of incremental shuttle and 6-minute walking tests. Physiotherapy 2007;93:261-266.

39. Kawakami Y, Terai T, Yamamoto H, Murao M. Exercise and oxygen inhalation in relation to prognosis of chronic obstructive pulmonary disease. Chest 1982;81(2):182-188.

40. Tojo N, Ichioka M, Chida M, Miyazato I, Yoshizawa Y, Miyasaka N. Pulmonary exercise testing predicts prognosis in patients with chronic obstructive pulmonary disease. Intern Med 2005;44(1):2025.

41. Takigawa N, Tada A, Soda R, Date H, Yamashita M, Endo S, et al. Distance and oxygen desaturation in 6-min walk test predict prognosis in COPD patients. Respir Med 2007;101(3):561-567.

42. Vandenbergh E, Clement J, Van de Woestijne KP. Course and prognosis of patients with advanced chronic obstructive pulmonary disease. Evaluation by means of functional indices. Am J Med 1973; 55(6):736-746

43. Christensen CC, Ryg MS, Edvardsen A, Skjonsberg OH. Relationship between exercise desaturation and pulmonary haemodynamics in COPD patients. Eur Respir J 2004;24(4):580-586.

44. Cotes JE, Gilson JC. Effect of oxygen on exercise ability in chronic respiratory insufficiency; use of portable apparatus. Lancet 1956; 270(6928):872-876.

45. Davidson AC, Leach R, George RJ, Geddes DM. Supplemental oxygen and exercise ability in chronic obstructive airways disease. Thorax 1988;43(12):965-971.

46. Leggett RJ, Flenley DC. Portable oxygen and exercise tolerance in patients with chronic hypoxic cor pulmonale. Br Med J 1977;2(6079): 84-86.

47. Bradley BL, Garner AE, Billiu D, Mestas JM, Forman J. Oxygenassisted exercise in chronic obstructive lung disease. The effect on exercise capacity and arterial blood gas tensions. Am Rev Respir Dis 1978;118(2):239-243.

48. Voduc N, Tessier C, Sabri E, Fergusson D, Lavallee L, Aaron SD. Effects of oxygen on exercise duration in chronic obstructive pulmonary disease patients before and after pulmonary rehabilitation. Can Respir J 2010;17(1):e14-e19.

49. Jolly EC, Di Boscio V, Aguirre L, Luna CM, Berensztein S, Gene RJ. Effects of supplemental oxygen during activity in patients with advanced COPD without severe resting hypoxemia. Chest 2001; 120(2):437-443.

50. Emtner M, Porszasz J, Burns M, Somfay A, Casaburi R. Benefits of supplemental oxygen in exercise training in nonhypoxemic chronic obstructive pulmonary disease patients. Am J Respir Crit Care Med 2003;168(9):1034-1042.

51. McDonald CF, Blyth CM, Lazarus MD, Marschner I, Barter CE. Exertional oxygen of limited benefit in patients with chronic obstructive pulmonary disease and mild hypoxemia. Am J Respir Crit Care Med 1995;152(5 Pt 1):1616-1619.

52. Liker ES, Karnick A, Lerner L. Portable oxygen in chronic obstructive lung disease with hypoxemia and cor pulmonale. A controlled double-blind crossover study. Chest 1975;68(2):236-241.

53. Wadell K, Henriksson-Larsen K, Lundgren R. Physical training with and without oxygen in patients with chronic obstructive pulmonary disease and exercise-induced hypoxaemia. J Rehabil Med 2001;33(5): 200-205.

54. Rooyackers JM, Dekhuijzen PN, Van Herwaarden CL, Folgering HT. Training with supplemental oxygen in patients with COPD and hypoxaemia at peak exercise. Eur Respir J 1997;10(6):1278-1284.

55. Moore RP, Berlowitz DJ, Denehy L, Pretto JJ, Brazzale DJ, Sharpe $\mathrm{K}$, et al. A randomised trial of domiciliary, ambulatory oxygen in patients with COPD and dyspnoea but without resting hypoxaemia. Thorax 2011;66(1):32-37. 


\section{AMBULATORY OXYGEN IN COPD}

56. Ram FS, Wedzicha JA. Ambulatory oxygen for chronic obstructive pulmonary disease. Cochrane Database Syst Rev 2002;(2)(2): CD000238.

57. Swinburn CR, Mould H, Stone TN, Corris PA, Gibson GJ. Symptomatic benefit of supplemental oxygen in hypoxemic patients with chronic lung disease. Am Rev Respir Dis 1991;143(5 Pt 1):913-915.

58. Morrison DA, Stovall JR. Increased exercise capacity in hypoxemic patients after long-term oxygen therapy. Chest 1992;102(2):542-550.

59. Bye PT, Esau SA, Levy RD, Shiner RJ, Macklem PT, Martin JG, et al. Ventilatory muscle function during exercise in air and oxygen in patients with chronic air-flow limitation. Am Rev Respir Dis 1985; 132(2):236-240.

60. Criner GJ, Celli BR. Ventilatory muscle recruitment in exercise with O2 in obstructed patients with mild hypoxemia. J Appl Physiol 1987; 63(1): 195-200.

61. Stevenson NJ, Calverley PM. Effect of oxygen on recovery from maximal exercise in patients with chronic obstructive pulmonary disease. Thorax 2004;59(8):668-672.

62. Payen JF, Wuyam B, Levy P, Reutenauer H, Stieglitz P, Paramelle $\mathrm{B}$, et al. Muscular metabolism during oxygen supplementation in patients with chronic hypoxemia. Am Rev Respir Dis 1993;147(3): 592-598.

63. Jakobsson P, Jorfeldt L. Long-term oxygen therapy may improve skeletal muscle metabolism in advanced chronic obstructive pulmonary disease patients with chronic hypoxaemia. Respir Med 1995; 89(7):471-476.

64. Nonoyama ML, Brooks D, Lacasse Y, Guyatt GH, Goldstein RS. Oxygen therapy during exercise training in chronic obstructive pulmonary disease. Cochrane Database Syst Rev 2007;(2):CD005372.

65. Wedzicha JA. Short burst oxygen therapy is helpful? Chron Respir Dis 2004;1(2):101-103.

66. Evans TW, Waterhouse JC, Carter A, Nicholl JF, Howard P. Short burst oxygen treatment for breathlessness in chronic obstructive airways disease. Thorax 1986;41(8):611-615.

67. Killen JW, Corris PA. A pragmatic assessment of the placement of oxygen when given for exercise induced dyspnoea. Thorax 2000; 55(7):544-546.

68. McKeon JL, Murree-Allen K, Saunders NA. Effects of breathing supplemental oxygen before progressive exercise in patients with chronic obstructive lung disease. Thorax 1988;43(1):53-56.

69. Nandi K, Smith AA, Crawford A, MacRae KD, Garrod R, Seed WA, et al. Oxygen supplementation before or after submaximal exercise in patients with chronic obstructive pulmonary disease. Thorax 2003; 58(8):670-673.

70. Woodcock AA, Gross ER, Geddes DM. Oxygen relieves breathlessness in "pink puffers". Lancet 1981;1(8226):907-909.

71. Lewis CA, Eaton TE, Young P, Kolbe J. Short-burst oxygen immediately before and after exercise is ineffective in nonhypoxic COPD patients. Eur Respir J 2003;22(4):584-588.

72. O'Driscoll BR, Neill J, Pulakal S, Turkington PM. A crossover study of short burst oxygen therapy (SBOT) for the relief of exerciseinduced breathlessness in severe COPD. BMC Pulm Med 2011;11: 23.

73. Marti S, Munoz X, Rios J, Morell F, Ferrer J. Body weight and comorbidity predict mortality in COPD patients treated with oxygen therapy. Eur Respir J 2006;27(4):689-696.

74. Flaherty KR, Andrei AC, Murray S, Fraley C, Colby TV, Travis $\mathrm{WD}$, et al. Idiopathic pulmonary fibrosis: prognostic value of changes in physiology and six-minute-walk test. Am J Respir Crit Care Med 2006;174(7):803-809.

75. Hallstrand TS, Boitano LJ, Johnson WC, Spada CA, Hayes JG, Raghu G. The timed walk test as a measure of severity and survival in idiopathic pulmonary fibrosis. Eur Respir J 2005;25(1):96-103.
76. Bye PT, Anderson SD, Woolcock AJ, Young IH, Alison JA. Bicycle endurance performance of patients with interstitial lung disease breathing air and oxygen. Am Rev Respir Dis 1982;126(6):1005-1012.

77. Harris-Eze AO, Sridhar G, Clemens RE, Gallagher CG, Marciniuk DD. Oxygen improves maximal exercise performance in interstitial lung disease. Am J Respir Crit Care Med 1994;150(6 Pt 1):16161622.

78. Douglas WW, Ryu JH, Schroeder DR. Idiopathic pulmonary fibrosis: impact of oxygen and colchicine, prednisone, or no therapy on survival. Am J Respir Crit Care Med 2000;161(4 Pt 1):1172-1178.

79. Crockett AJ, Cranston JM, Antic N. Domiciliary oxygen for interstitial lung disease. Cochrane Database Syst Rev 2001;(3)(3): CD002883.

80. Bradley B, Branley HM, Egan JJ, Greaves MS, Hansell DM, Harrison NK, et al. Interstitial lung disease guideline: the British Thoracic Society in collaboration with the Thoracic Society of Australia and New Zealand and the Irish Thoracic Society. Thorax 2008; 63(Suppl 5):v1-58. Erratum in: Thorax 2008;63(11):1029.

81. Roger VL, Go AS, Lloyd-Jones DM, Adams RJ, Berry JD, Brown TM, et al. Heart disease and stroke statistics: 2011 update: a report from the American Heart Association. Circulation 2011;123(4):e18e209.

82. Sasayama S, Izumi T, Seino Y, Ueshima K, Asanoi H, CHF-HOT Study Group. Effects of nocturnal oxygen therapy on outcome measures in patients with chronic heart failure and cheyne-stokes respiration. Circ J 2006;70(1):1-7.

83. Javaheri S, Ahmed M, Parker TJ, Brown CR. Effects of nasal O2 on sleep-related disordered breathing in ambulatory patients with stable heart failure. Sleep 1999;22(8):1101-1106.

84. Krachman SL, D'Alonzo GE, Berger TJ, Eisen HJ. Comparison of oxygen therapy with nasal continuous positive airway pressure on Cheyne-Stokes respiration during sleep in congestive heart failure. Chest 1999;116(6):1550-1557.

85. Restrick LJ, Davies SW, Noone L, Wedzicha JA. Ambulatory oxygen in chronic heart failure. Lancet 1992;340(8829):1192-1193.

86. Russell SD, Koshkarian GM, Medinger AE, Carson PE, Higginbotham MB. Lack of effect of increased inspired oxygen concentrations on maximal exercise capacity or ventilation in stable heart failure. Am J Cardiol 1999;84(12):1412-1416.

87. Abernethy AP, Currow DC, Frith P, Fazekas B. Prescribing palliative oxygen: a clinician survey of expected benefit and patterns of use. Palliat Med 2005;19(2):168-170.

88. Uronis H, McCrory DC, Samsa G, Currow D, Abernethy A. Symptomatic oxygen for non-hypoxaemic chronic obstructive pulmonary disease. Cochrane Database Syst Rev 2011;(6):CD006429.

89. Abernethy AP, McDonald CF, Frith PA, Clark K, Herndon JE 2nd, Marcello J, et al. Effect of palliative oxygen versus room air in relief of breathlessness in patients with refractory dyspnoea: a doubleblind, randomised controlled trial. Lancet 2010;376(9743):784-793.

90. Centers for Medicare and Medicaid Services. Medicare Coverage Database, NCD Chapter 240.2. Available from: http://www.cms. hhs.gov/mcd/index_chapter_list.asp. Accessed December 6, 2012.

91. Arnold E, Bruton A, Donovan-Hall M, Fenwick A, Dibb B, Walker E. Ambulatory oxygen: why do COPD patients not use their portable systems as prescribed? A qualitative study. BMC Pulm Med 2011;11:9.

92. Casaburi R, Porszasz J, Hecht A, Tiep B, Albert RK, Anthonisen $\mathrm{NR}$, et al. Influence of lightweight ambulatory oxygen on oxygen use and activity patterns of COPD patients receiving long-term oxygen therapy. COPD 2012;9(1):3-11.

93. National Heart, Lung and Blood Institute. Effectiveness of long-term oxygen therapy in treating people with chronic obstructive pulmonary disease (the Long-term Oxygen Treatment Trial [LOTT]). ClinicalTrials no. NCT00692198 http://clinicaltrials.gov/ct2/show/ NCT00692198. Accessed October 25, 2012. 


\section{Discussion}

Kallet: Being a former ARDS Network coordinator, I just want to say that I feel your pain about the problems of enrolling and randomizing patients into a clinical trial. I'm intrigued by how $\mathrm{O}_{2}$ toxicity relates to low-flow $\mathrm{O}_{2}$ therapy. I deal with this a little bit in my paper. Just finding an increased expression of pro-inflammatory mediators doesn't necessarily indicate something pathologically serious is going on. Did those studies measure anti-inflammatory mediators at the same time? If you have an inflammatory response from radical $\mathrm{O}_{2}$ species, you're basically going to have some sort of a counter-response, and it would be important to know that. Also, how important is the rise in pro-inflammatory mediators in disease progression? As a lover of strong coffee and good wine, an analogy comes to mind. Studies of coffee and alcohol have found that they produce trauma to your stomach lining, but it doesn't necessarily mean anything serious, at least in the short term. Does anybody have information on low-flow $\mathrm{O}_{2}$ toxicity?

Criner: I wanted to put the counterargument out there. If you look at any chemokine or pro-inflammatory mediator, there's no global comprehensive description of all types of inflammatory and anti-inflammatory mediators. I could show you slides showing the anti-inflammatory effects of $\mathrm{O}_{2}$ therapy on decreasing neutrophil expression or inflammatory mediators that are found locally or systemically, but there is an imbalance in the literature as to whether it's pro- or anti-inflammatory.

Kallet: Julio Turrens, who's one of the leading experts on mitochondrial damage, basically says that, under normobaric situations-unless it's the lungs we're talking about-it's really not an issue for other organs. ${ }^{1}$
Kevin Ward: It's difficult to take out the single-organ perspective of lung function without a concomitant coupling with the rest of the cardiovascular system. In terms of the metabolics and how these people respond, I would think you would be able to sort some of this out. Perhaps people who don't respond don't have an appropriate increase in cardiac output to activity, so you can't compensate for that just by raising arterial $\mathrm{O}_{2}$ content with supplemental $\mathrm{O}_{2}$. Or, in terms of afterload, reducing more people who don't respond so maybe they become responders. How do you differentiate between responders and non-responders, and can you make non-responders into potential responders if you're not going to take into account things like metabolics?

Criner: When we were designing the LOTT $^{2}$ we discussed how to characterize the patients and whether they show predominately pulmonary benefit, or should we just forget about characterizing that? With what you mention, we have a patient group here who is older, frail, and with substantial comorbidities, including heart failure, cardiovascular disease, diabetes, or obesity, which all worsen their dyspnea and contribute to a linkage of pulmonary and cardiac dysfunction. After a laborious year and a half of designing the trial, we decided that if a patient comes into an emergency department or a hospital and we give them $\mathrm{O}_{2}$ and it improves their cardiac output, their cerebrovascular function, and it has an all-cause benefit on decreasing why they got admitted to the hospital or why they die, we don't exactly care if it improves the lung or the heart or red blood cell mass or decreases risk of stroke: we're looking for global patient benefit. It would be so exhaustive to characterize and then sub-sub-phenotype the patients by their physiologic criteria, where there's massive overlap in these patients. We decided it wasn't practical to do that.
Kevin Ward: But wouldn't you agree that it's eventually going to need to be done?

Criner: I think it probably will need to be done if it shows a benefit or an overwhelming negative and there's heterogeneity in the response. But overall I think that if it shows a benefit for this patient group-if it improves survival or hospitalization-I think that will carry the day.

Lewarski:* In regard to the study that discussed the various subjective reasons why home oxygen patients didn't want to use their prescribed ambulatory $\mathrm{O}_{2}$ system, I believe the study was conducted in the United Kingdom, so these results might not translate globally. In the United Kingdom's home oxygen program, they use E cylinders almost exclusively as the ambulatory $\mathrm{O}_{2}$ system. The United Kingdom's health care system is very different from that of the United States, so those results may represent only the United Kingdom.

In regard to Rich Casaburi and colleagues' recent work ${ }^{3}$ comparing ambulation and activity in patients using E cylinders versus small, lightweight cylinders, the optimist in me saw about a $40 \%$ increase in ambulation in the small-cylinder group. In regard to the belief that the $\mathrm{O}_{2}$ device is the root of the ambulation problem, and if we give people the ideal portable $\mathrm{O}_{2}$ system they'll be out gallivanting around for 9 hours a day, I'm not quite sure we understand what this typically elderly patient population actually does in a given day or week. Are there any published comparisons to a control group of COPD patients who are not $\mathrm{O}_{2}$ dependent that measure and compare their activities of daily living and the amount of time they spend away from home versus those who are on $\mathrm{O}_{2}$ ? In my experience, even with the most ac-

\footnotetext{
* Joseph S Lewarski RRT FAARC, Invacare, Elyria, Ohio.
} 
tive, adherent $\mathrm{O}_{2}$ patients you rarely see them using their ambulatory $\mathrm{O}_{2}$ for more than 2 hours a day.

Criner: In that study ${ }^{3}$ the patients are more severe than in LOTT: $75 \%$ of the group that was normoxic at rest desaturated. I think we'll probably get the answer from that trial, because those patients were less impaired than the COPD patients in LOTT.

McCoy: How are you going to control the variability of the $\mathrm{O}_{2}$ products? I heard the patients are going to use their own $\mathrm{O}_{2}$ systems, and those systems are highly variable. And how do you make sure they're oxygenated at all activity levels?

Criner: The patients come in on a regular basis and have their $\mathrm{O}_{2}$ saturation measured at rest and during a 6-minute walk test, and they're titrated to maintain $\mathrm{S}_{\mathrm{pO}_{2}}$ at $90 \%$ at rest and exertion. There is a uniform sort of prescription that patients get for $\mathrm{O}_{2}$ therapy: a stationary and a lightweight ambulatory device, which is in the policy that goes out to all the vendors involved with this, and they know which are LOTT patients. It's coded and paid for by Medicare. So it's standardized in that way.

Owens: What is the pre-randomization treatment of these patients? How many times are you checking the $\mathrm{O}_{2}$ saturation? Is there a stabilization or pulmonary rehabilitation period before they get in, or is it just usual care before they're randomized?

Criner: It's standard community care: there's no phase-in period for pulmonary rehabilitation. The GOLD [Global Initiative for Chronic Obstructive Lung Disease] guidelines ${ }^{4}$ are used for optimizing medical care, and there are checklists on what medications the patients should be on.

Owens: And is it resting hypoxemia on one measurement or two?

Criner: We're using a quantitative system where we're measuring it for 5 minutes at rest, then there's a one minute period in which the desaturation has to occur.

Heffner: During the designing of the trial were there any discussions that might provide insight into potential political or payer implications if it's a negative study?

Criner: It's not clear what the implications would be. We were told from the very beginning that Medicare has been involved with the meetings, and, depending on what we showed-and we were very careful with what we used for measures to describe the eligible patient population-that they were measures that could be used by anybody. If the trial is negative in harm, we don't know what changes in Medicare guidelines would occur.
Heffner: Akin to sleep apnea with CPAP, where providers submit electronic data cards to verify use and maintain payment, has their been any discussion regarding installing monitoring cards into $\mathrm{O}_{2}$ ambulatory equipment to verify that patients actually use their equipment and thereby justify payment?

Criner: We designed a detailed adherence sub-study that was going to use the kind of device that was designed by the COPD Clinical Research Network, but that didn't come to be. Instead we're measuring patient usage by tanks delivered and selfreported days of use, but we don't have objective monitoring for each patient.

\section{REFERENCES}

1. Turrens JF. Mitochondrial formation of reactive oxygen species. J Physiol 2003; 552(2):335-344.

2. Bailey CM et al; National Heart, Lung, and Blood Institute. Effectiveness of long-term oxygen therapy in treating people with COPD (the long-term oxygen treatment trial [LOTT]). http://clinicaltrials.gov/ct2/show/ NCT00692198. Accessed July 23, 2012.

3. Casaburi R, Porszaz J, Hecht A, Tiep B, Albert RK, Anthonisen NR, et al; COPD Clinical Research Network. Influence of lightweight ambulatory oxygen on oxygen use and activity patterns of COPD patients receiving long-term oxygen therapy. COPD 2012;9(1):3-11.

4. Global Initiative for Chronic Obstructive Lung Disease. Global strategy for the diagnosis, management, and prevention of COPD. Revised December 2011. http:// www.goldcopd.org/uploads/users/files/ GOLD_Report_2011_Feb21.pdf. Accessed July 23, 2012.

This article is approved for Continuing Respiratory Care Education credit. For information and to obtain your CRCE

(free to AARC members) visit

www.rcjournal.com 